\title{
Diretrizes de design de interfaces para terceira idade: guia projetual para o desenvolvimento de interfaces em refrigeradores voltados ao público idoso
}

Victor Henrique Fagundes (Currículo Lattes) Adriane Shibata Santos (Currículo Lattes)

\section{INTRODUÇÃO}

A crescente evolução tecnológica computacional e a rápida disseminação da interatividade virtual são fatores que vêm direcionando a sociedade para uma constante adaptação aos novos cenários e padrões tecnológicos aos quais está invariavelmente sendo inserida.

Nos dias atuais, considerando a rotina de uma grande cidade, as pessoas estão propícias a inúmeras interações com diversos tipos de tecnologias, desde um simples acionamento do elevador ao sair de casa, por meio do painel de um carro, em um caixa automático de banco, até mesmo ao utilizar um telefone. Estes e muitos outros 
momentos fazem com que as pessoas tenham, de alguma maneira, contato com a tecnologia em forma de sistemas interativos.

Atualmente se entende por interação humano-computador o campo de estudo interdisciplinar, que tem como objetivo compreender como e por que as pessoas utilizam (ou não utilizam) a tecnologia da informação, focando no estudo de como projetar, implementar e utilizar sistemas computacionais interativos (SANTA ROSA; MORAES, 2008).

Segundo Preece et al. (2005), o objetivo do estudo da interação entre homem-máquina é trazer a abordagem da usabilidade para dentro do processo de desenvolvimento deses sistemas. Na essência, o desafio é criar produtos interativos que sejam fáceis, eficientes e amigáveis ao uso, pela perspectiva dos usuários.

Sendo assim, a usabilidade, que tem em sua essência a busca por uma simbiose entre interface, usuário, tarefa e ambiente, no processo de desenvolvimento de produtos físicos ou digitais, com o tempo assumiu importância muito maior do que no passado, quando os usuários só experimentavam a usabilidade do produto após a compra (SANTA ROSA; MORAES, 2008).

Nesse processo evolutivo, os resultados que possivelmente se tornaram mais constantes e intensos foram os que envolviam os computadores pessoais e seus programas. Sua evolução fez com que se tornasse a mais popular de todas as máquinas e a responsável por uma revolução nos hábitos e na atual organização social, impulsionados pela disseminação da tecnologia touch, a qual trouxe para o mercado uma nova referência de interação.

Esse movimento impôs uma rápida adaptação nos demais setores industriais, fazendo com que monitores de computador, televisores, máquinas fotográficas, filmadoras, entre outros, incorporassem esse tipo de tecnologia, conforme representado na Figura 1. 
Figura 1 - Aplicação da tecnologia touch em vários segmentos
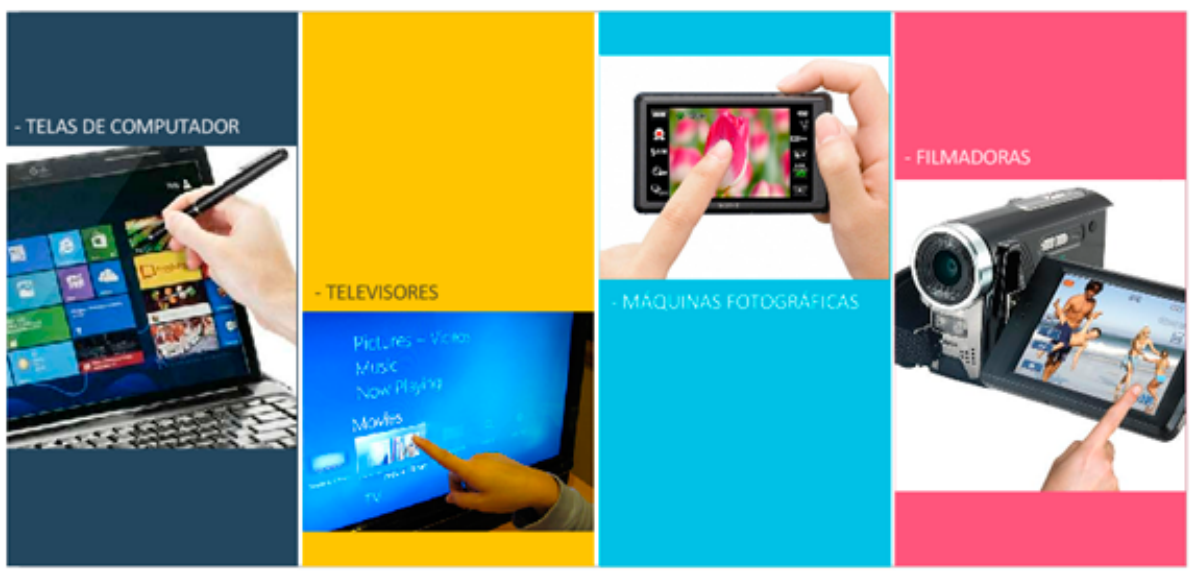

Fonte: Fagundes (2015)

Entre os grandes segmentos industriais de bens de consumo, o mais recente movimento no sentido da aplicação de novas tecnologias de interação foi o setor de eletrodomésticos, que no fim da primeira década de 2000 começou a expor espaços em feiras de tecnologias junto os eletroeletrônicos. Na lista dos que mais sofreram intervenções nesse sentido está o refrigerador, que é um dos eletrodomésticos mais presentes no cotidiano das famílias brasileiras.

Essa crescente demanda fez com que a categoria recebesse maior atenção nas indústrias do segmento por meio da incorporação de um grande número de incrementos tecnológicos, ilustrados na Figura 2. 
Figura 2 - Refrigeradores nacionais com interface touch

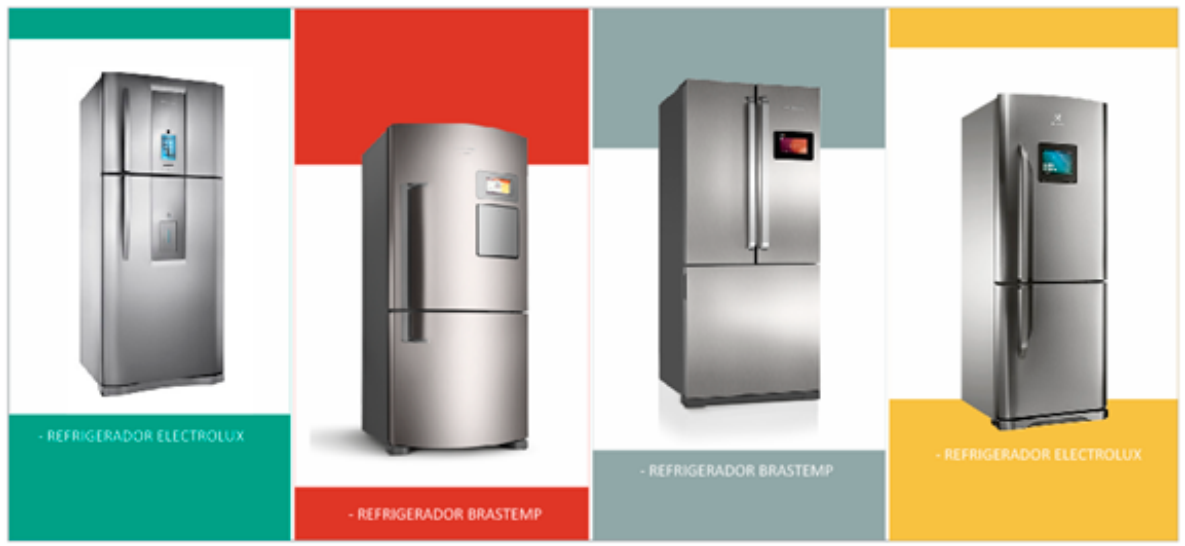

Fonte: Fagundes (2015)

Paralelamente a esses acontecimentos, e a exemplo do que já vem acontecendo no cenário internacional, a última Pesquisa Nacional por Amostra de Domicílios (PNAD) (IBGE, 2013) mostrou que o Brasil vem sofrendo profundas alterações na base e no topo da pirâmide nas últimas décadas. Amparado pela maior expectativa de vida, há um aumento acentuado no número de idosos, enquanto os grupos de 0 a 24 anos sofrem uma contínua redução.

Considera-se idosa a pessoa com 60 anos ou mais, de acordo com a recomendação da (OMS - World Health Organization [WHO]) para países em desenvolvimento (WHO, 2014). No mesmo relatório da PNAD 2012, é possível encontrar algumas projeções baseadas nos dados levantados, as quais mostram que em 2030 o grupo de idosos de 60 anos ou mais será maior que o grupo de crianças com até 14 anos de idade, e em 2055 a participação de idosos na população total será maior que a de crianças e jovens com até 29 anos de idade, fazendo com que o Brasil deixe de ser um país jovem para se tornar um país em sua grande maioria maduro. 
Essas transformações trazem não apenas alterações econômicas, mas também sociais e comportamentais. Considerando que as novas gerações demonstram cada vez mais intimidade e atração pelos artefatos tecnológicos e, assimilando facilmente as mudanças, a geração adulta e mais velha, nascida anterior à disseminação do universo digital e da internet, ainda não consegue acolher e extrair tranquilamente os benefícios dessas tecnologias com a mesma facilidade de assimilação dos jovens.

Essa questão tem se tornado mais importante com a crescente popularização da internet, o que evidencia a necessidade de se pensar diretrizes de acessibilidade na web, abrindo os caminhos para que mais pessoas possam se sentir incluídas nessa sociedade tecnológica. Para Vieira e Santa Rosa (2014), os idosos que utilizam o computador sentem-se menos excluídos e melhoram sua conexão com o mundo externo.

O fato é que, consciente ou inconscientemente, desconsiderando as implicações sociais relacionadas ao envelhecimento, designers deixam de auxiliar no processo de socialização tecnológica e de agregar tanto valor quanto poderiam a produtos e softwares.

Diante desse quadro surge o seguinte questionamento: como melhorar a relação de uso entre os usuários da terceira idade e refrigeradores, considerando os avanços tecnológicos das interações no segmento de eletrodomésticos?

A partir desse questionamento, a pesquisa aqui apresentada teve por objetivo principal trazer melhorias a pessoas da terceira idade nas relações de uso de eletrodomésticos dotados de tecnologias de interação. Buscou o entendimento do processo de design de interfaces, bem como a aplicação de suas ferramentas voltadas à arquitetura da informação, necessidades dos usuários e diretrizes de usabilidade, descritos a seguir. 


\section{DESIGN DE INTERFACES}

A área de design de interfaces, ou design de interação humanocomputador, tem como objetivo principal o projeto edesenvolvimento de interfaces com o propósito de aprimorar sistemas computacionais nos quais usuários possam executar suas tarefas com segurança, eficácia e satisfação (SANTA ROSA; MORAES, 2008).

Resumidamente, o processo de design de interfaces requer o entendimento das necessidades dos usuários, equilibrando conceitos de design a funcionalidades técnicas, pautados pelas diretrizes de usabilidade, conforme Figura 3.

Figura 3 - Processo básico de design de interfaces

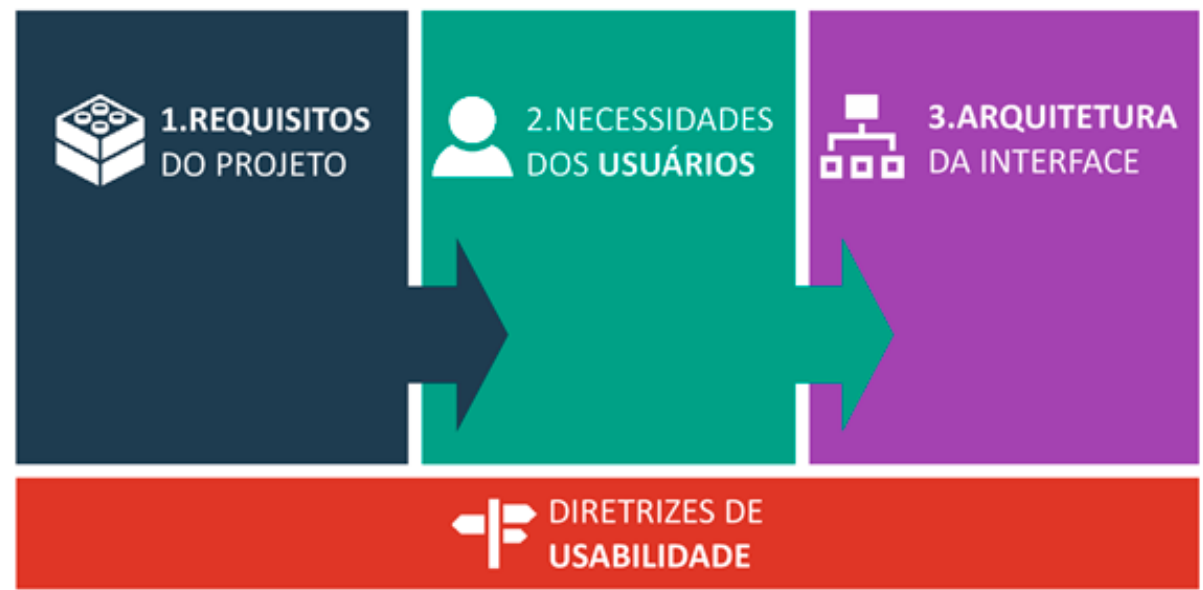

Fonte: Fagundes (2015)

Este projeto não teve por objetivo o desenvolvimento de uma interface, mas sim de diretrizes projetuais, de modo que o processo aplicado partiu de uma análise da arquitetura de informação das principais interfaces de refrigeradores existentes no mercado nacional, para então posteriormente entender as necessidades dos usuários da terceira idade e finalmente propor as diretrizes para o 
desenvolvimento de interfaces para refrigeradores voltadas ao público da terceira idade.

Para essas atividades foram selecionados três modelos de refrigeradores: 1) Brastemp Side Inverse 540 litros, 2) Electrolux I-Kitchen 542 litros e 3) Brastemp Ative 429 litros, apresentados com suas características na Figura 4.

Figura 4 - Produtos selecionados e suas principais características

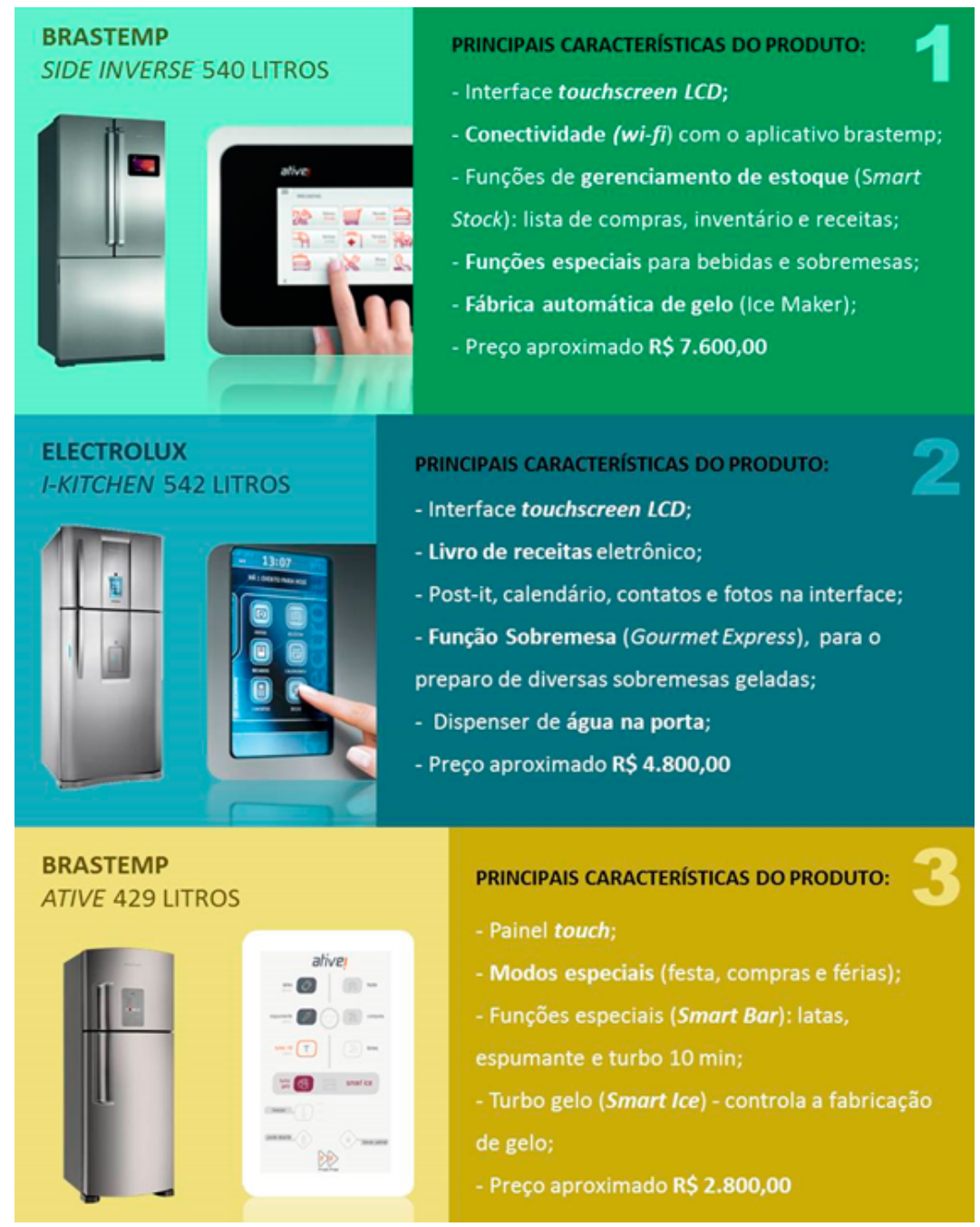

Fonte: Fagundes (2015) 
Para compreender a arquitetura das três interfaces, optou-se por estruturar uma análise baseada nos princípios de arquitetura da informação descritos por Spencer (2010), porém foram considerados apenas os itens relacionados à estrutura geral e elementos de navegação, sendo:

a) Características gerais: de maneira geral, verificou-se que as três interfaces apresentam características tecnológicas distintas entre elas, desde PCB (placa impressa com tinta condutiva sensível ao toque), que é considerado o modelo mais barato de tecnologia touch, até o capacitive touch, que é a mesma tecnologia utilizada nos principais smartphones;

b) Estrutura visual: em se tratando de estrutura visual, as maiores diferenças ficam entre os modelos com telas gráficas navegáveis e o modelo com interação em tela única. O modelo Brastemp Ative, por não ser navegável, apresenta características mais convencionais, com agrupamento de funções por afinidade e semântica gráfica próxima à utilizada em painéis de controles com botões físicos. Já os modelos Brastemp Side Inverse e Electrolux I-Kitchen trazem características visuais mais elaboradas e seguem padrões amplamente utilizados em tablets e smartphones;

c) Tipos de interação: os três modelos analisados não apresentam novidades quando comparados a outros produtos com tecnologia touch. Toda a navegação é baseada em toques, deslizes verticais e horizontais e pressão por alguns segundos;

d) Padrões de fluxo de trabalho da interface: dois modelos analisados (Brastemp Side Inverse e Electrolux I-Kitchen) apresentam o mesmo tipo de padrão de fluxo de trabalho, baseado em 3 diferentes níveis, com uma estrutura hierárquica bem definida entre a tela inicial, menus e funções. 
Com as 3 interfaces analisadas sob a ótica da arquitetura da informação, foi possível verificar as principais características e diferenciais de cada modelo, bem como torná-los aptos a serem utilizados em pesquisas com usuários, já que o conhecimento prévio dos produtos testados é requisito básico para a execução de testes de usabilidade.

\section{PESQUISA COM PÚBLICO-ALVO}

A presente etapa apresenta o entendimento das necessidades dos usuários da terceira idade. Para alcançar uma maior assertividade e eficácia na abordagem, o público-alvo foi segmentado segundo os seguintes critérios demográficos e psicográficos:

- Pessoas com mais de 60 anos presentes nas classes A e B;

- Ambos os sexos, solteiros ou casados, que possuam smartphones ou estejam habituados com tecnologias de interação.

A partir desta segmentação, optou-se pela aplicação das três ferramentas para o entendimento das necessidades do usuário, sendo o grupo de foco, teste de usabilidade e pesquisa contextual.

O recrutamento dos participantes respeitou diretrizes apontadas na fundamentação teórica da pesquisa e os critérios apresentados anteriormente. Foram então selecionados 15 indivíduos residentes em Joinville/SC e região, 10 mulheres e 5 homens, os quais foram divididos e posicionados nas atividades conforme a Figura 5. Para a definição da proporção de gênero utilizada no recrutamento e na aplicação das ferramentas, considerou-se também como critério a frequência de envolvimento na realização de atividades domésticas deste grupo. 
Figura 5 - Esquema de recrutamento e divisão de usuários

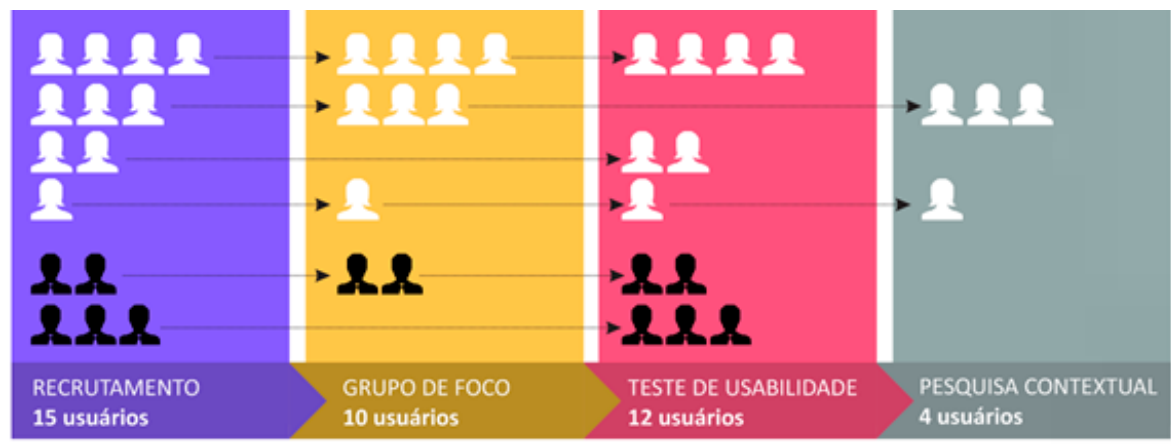

Fonte: Fagundes (2015)

Com o perfil determinado, participantes recrutados e estrutura de aplicação disponível, iniciou-se a execução a partir do grupo de foco, seguido pelos testes de usabilidade e pela pesquisa contextual.

\section{Aplicação do grupo de foco}

A atividade que teve como objetivo compreender (1) como a evolução tecnológica em produtos afeta a rotina nas atividades do lar, em especial no ambiente da cozinha, (2) a relação dos idosos com produtos dotados de tecnologias de interação, e (3) a percepção de benefícios trazidos pelas tecnologias trouxe como principais conhecimento gerados os seguintes tópicos:

1. Quanto à relação dos idosos com as atividades do lar:

- não se consideram idosos e possuem um grande senso de responsabilidade pelo lar em que vivem;

- em se tratando da aquisição produtos, apesar de serem fiéis a alguns modelos e marcas, frequentemente experimentam novidades e lançamentos;

- a segurança é fator predominante em suas escolhas e a família se apresenta como prioridade e o ponto emocional mais forte. 
2. Quanto à relação dos idosos com a tecnologia:

- dependem sempre de um incentivador que apresente e ensine como utilizar artifícios tecnológicos, fazendo com que o uso seja de forma superficial;

- estão habituados a computadores e telas touch e sempre relacionam a tecnologia com a conectividade; - a tecnologia é apontada como uma opção para suprir a solidão e o tempo ocioso, por meio do entretenimento e do uso diário da internet;

- a aceitação e aquisição de produtos tecnológicos estão diretamente vinculadas à confiança e relevância.

3. Quanto aos benefícios das novas tecnologias:

- uxiliam na comunicação e nos relacionamentos com amigos e familiares e permitem organizar melhor o dia a dia por meio de agendas e lembretes;

- facilitam a busca de informações, a localização por meio de mapas e trazem mais opções de entretenimento.

A aplicação dessa ferramenta permitiu o entendimento de diversos fatores que envolvem a relação entre idosos e tecnologias, em especial características voltadas ao interesse e percepções sobre o tema proposto. Destaca-se que, apesar dos entrevistados mencionarem o uso frequente de computadores e smartphones e compreenderem os inúmeros benefícios trazidos pelas evoluções tecnológicas, a relação com produtos providos de tecnologias de interação ainda não se mostra natural e fácil. 


\section{Aplicação dos testes de usabilidade}

A segunda atividade voltou-se à avaliação da usabilidade das interfaces dos três modelos de refrigeradores definidos anteriormente e visou entender a forma de interação e as dificuldades encontradas pelos usuários da terceira idade durante o uso.

Ao todo foram executados doze testes individuais com usuários, seguindo roteiro de quatro tarefas pré-determinadas que trouxeram diversos aprendizados e estão resumidos a seguir:

1. Evitam desbravar a interface - por possuírem dificuldades de localização e navegação pela interface, os usuários idosos entendem que todas as funções oferecidas pela interface se encontram na primeira página e apresentaram dificuldades de interpretação dos diferentes padrões ou lógicas na mesma função.

2. Preferem linguagens diretas - com um aprendizado mais lento, preferem não pensar antes de executar a ação, preferindo linguagens e lógicas de usos claras e diretas.

3. Entram em pânico facilmente - por errarem mais de uma vez a mesma ação, utilizam constantemente a saída de emergência e preferem indicações/pistas claras do caminho a ser seguido.

Devido a suas características observatórias, além da visualização das maiores dificuldades na interação com as interfaces testadas, com a aplicação dos testes de usabilidade também foi possível compreender alguns impactos de características físicas e psicológicas desse público na forma de utilização das tecnologias. Como exemplo, destacam-se a interação com toques menos precisos, dificuldade de leitura em textos com fontes reduzidas e a expressão de culpa ao selecionar um botão ou função equivocadamente. 


\section{Aplicação da pesquisa contextual}

A terceira e última atividade aplicada para o entendimento das necessidades dos usuários foi a pesquisa contextual.

A atividade foi aplicada diretamente no ambiente doméstico de 4 participantes do sexo feminino, selecionadas a partir da atividade de grupo de foco, e trouxe informações sobre a compreensão da rotina dos idosos em atividades que envolvessem equipamentos com tecnologias de interação, em especial no ambiente da cozinha, as quais estão resumidamente descritas a seguir:

1. São conservadores nas atividades domésticas - simplicidade e praticidade direcionam as escolhas para o dia a dia do lar onde, apesar de estarem habituados com computadores, tablets e smartphones, optam sempre por produtos menos tecnológicos e já conhecidos.

2. Tecnologia é comunicação - foi possível observar que a tecnologia está sempre ligada a atividades de lazer e representa o canal de contato com familiares e amigos, além de ser uma fonte de informações e entretenimento.

Com os resultados da pesquisa contextual, finalizou-se a aplicação das ferramentas de entendimento das necessidades dos usuários e consequentemente a etapa de pesquisas práticas da metodologia proposta.

\section{DESENVOLVIMENTO DAS DIRETRIZES PROJETUAIS}

Com o objetivo de sobrepor os dados obtidos das diferentes etapas da pesquisa, foi realizada inicialmente uma análise que permitiu tanto a verificação das informações bibliográficas ante os resultados das atividades práticas, quanto confrontar afirmações dos 
usuários nos grupos de foco e atitudes observadas nas pesquisas contextuais.

O resultado dessa análise gerou um grupo de sete diretrizes, as quais buscam abranger de forma sucinta os principais conhecimentos gerados na pesquisa, sendo desde tópicos voltados ao significado da aplicação das tecnologias de interação em refrigeradores, até elementos que visam auxiliar no direcionamento do projeto da arquitetura da interface.

As diretrizes foram elaboradas para compor o processo de desenvolvimento de interfaces para refrigeradores e atuar como estímulo à reflexão sobre o público da terceira idade, e o resultado está em forma de infográfico na Figura 6. 
Figura 6 - Desenvolvimento gráfico das diretrizes propostas

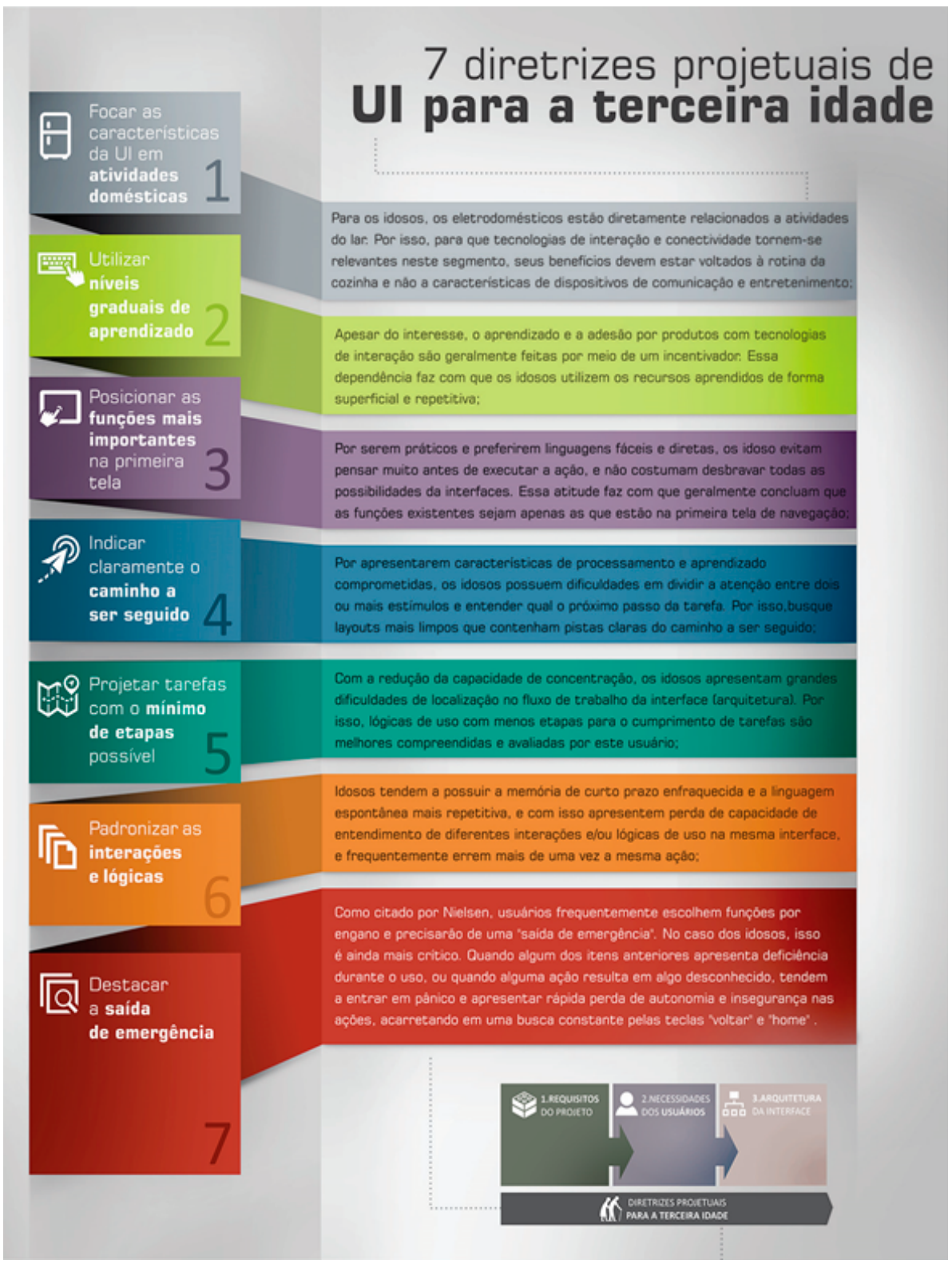

Fonte: Fagundes (2015) 


\section{CONSIDERAÇÕES FINAIS}

Entendendo o contexto em que projetistas de interfaces estão inseridos, pode-se considerar, pelo resultado apresentado, que as diretrizes venham a se tornar uma ferramenta influenciadora no que diz respeito ao processo de desenvolvimento de novas interfaces para refrigeradores, tornando-se um conjunto de informações e premissas que podem auxiliar na composição de projetos que façam sentido para o público da terceira idade.

DesSe modo, a pesquisa resultou numa ampla reflexão sobre a relação do idoso com a tecnologia, cujo desfecho conclusivo é o guia projetual para novas interfaces com foco na terceira idade.

Vale ressaltar que, considerando as diversas diretrizes de usabilidade existentes, que de certa forma atendem ao público da terceira idade, o resultado desta pesquisa não compreende a substituição dos modelos atuais, mas sim sua aplicação como complemento e suporte a projetos que favoreçam esses usuários. 


\section{REFERÊNCIAS}

FAGUNDES, V. H. Diretrizes de design de interfaces para terceira idade: guia projetual para o desenvolvimento de interfaces em refrigeradores voltados ao público idoso. 2015. 96 f. Dissertação (Mestrado em Design) - Universidade da Região de Joinville-Univille, Joinville, 2015.

IBGE - Instituto Brasileiro deGeografia eEstatística. Pesquisa Nacional por Amostras de Domicílios 2012. Disponível em: <http://www. ibge.gov.br/home/estatistica/populacao/trabalhoerendimento/ pnad2012/default_brasil.shtm>. Acesso em: 10 mar. 2013.

NIELSEN, J. Usability Engineering. Mountain View, CA, EUA: Academic Press,1993.

PREECE, J.; ROGERS, Y.; SHARP, H. Design da Interação: além da Interação homem-computador. Porto Alegre: Bookman, 2005.

SANTA ROSA, J. G.; MORAES, A. M. Avaliação e projeto no design de interfaces. Teresópolis, RJ: 2AB, 2008.

SPENCER, D. A Practical Guide to Information Architecture. United Kingdom: Five Simple Steps, 2010.

VIEIRA, M. C.; SANTA ROSA, L. M. C. O uso do computador e da Internet e a participação em cursos de informática por idosos: meios digitais, finalidades sociais. In: SIMPÓSIO BRASILEIRO DE INFORMÁTICA, XX, 2009, Florianópolis. Disponível em: <http://www.niee.ufrgs.br/ eventos/SBIE/2009/conteudo/artigos/completos/61684_1.pdf >. Acesso em: 18 mai. 2014.

WHO. World Health Organization. Disponível em: <http://www. who.int/en/>. Acesso em 23 mar. 2014. 
